\title{
The Prophecy of Ulrich Beck: Signposts for the Social Sciences
}

\author{
Gabe Mythen, Adam Burgess and Jamie K. Wardman
}

\begin{abstract}
This special issue on the legacy of Ulrich Beck is aimed to stimulate reflection both on the specific uses to which Beck's conceptual and theoretical apparatus can be put within risk studies and the wider significance of his academic project for the social sciences. In this end-piece we draw out the key themes which surface in the different contributions relating to five particular areas: the nature of risk; advancements in methods; issues of non-knowledge and uncertainty; the development of cosmopolitan risk communities; and the situated character of individualization. We discuss the implications of the accounts contained in this special issue and reflect on the impact and influence of Beck's sustained engagement with colleagues around the globe, concluding that the concepts and methods that Beck bequeathed the social sciences are set to live on and thrive.
\end{abstract}

In this end-piece we will draw out the key themes which surface in the different contributions to this special edition on the legacy of Ulrich Beck. In bringing the collection together, we wish to stimulate reflection on both the specific uses to which Beck's conceptual and theoretical apparatus can be put within risk studies and the wider significance of his academic project for the social sciences. The preceding articles bear testament to the depth of Ulrich Beck's body of work. Each one of the contributors has, in distinct ways, been impacted and influenced by it. We all have our own personal recollections of Beck himself. Those of us who knew him were energized by the fizz of ideas that seemed literally to spill out from his core, struck by his eagerness to listen and reflect, moved by his unstinting generosity of spirit and charmed by the wry yet gentle sense of humor typified by his penchant for cataloguing the absurdities of modern life. He embraced and learnt from criticism, enthusiastically encouraging rater than dismissing those developing critiques of his concepts and frameworks. 
Notwithstanding these assorted memories of a scholar considered by Anthony Giddens (2015) to have been 'the greatest sociologist of his generation', the modest ambition of this collection has been to highlight areas in which Beck's work can be drawn upon to grapple with the complexities of an unpredictable and constantly evolving 'runaway world'. Although it is not possible to do justice to the span and reach of Beck's thought, those contributing to this endeavor have focused on distinct aspects of his thinking to suggest ways in which his contribution can be nurtured and developed. Beck always strived hard to peek behind the curtain, to advance what he referred to as 'projective social theory' (Beck 1992: 9). This mode of inquiry was designed to grapple not only with the present, but to glimpse the contours of the future. This focus on understanding the 'not-yet-arrived' was integral to both his academic method and his esoteric style of writing. Beck was a true querdenker, a lateral thinker who made it his business to unsettle and provoke (see Kaldor and Selchow 2015; Mythen 2014).

The implications of the accounts contained in this special issue relate to five particular areas: the nature of risk; advancements in methods; issues of non-knowledge and uncertainty; the development of cosmopolitan risk communities; and the situated character of individualization. Mads Sørensen's opening piece focused on the strides made by Beck in reflecting upon the unquantifiable risks that characterize 'reflexive modernization'. Sorensen provides a thorough and nuanced account of Beck's conceptualization of risk that is also sensitive to its shortcomings and modifications. In doing so he taps into important debates about epistemologies and ontologies of risk that are worthy of further exploration. Insofar as Beck was often criticized for assuming an uncertain position between pure social constructionism and realism, the conundrum of 
how best to 'approach' risk remains unresolved. While many empirical studies in risk research have followed the realist paradigm established in science, engineering and medicine, a more theoretically inclined band of social constructionist thinkers have challenged this trajectory, being inspired by the theoretical perspectives offered by Douglas, Ewald and Foucault. Beck himself refused to adopt a singular lens, instead focusing on the intersection between 'the risk itself and public perception of it' (Beck 1992: 55). While this might well have made him an easy target for camp sitters on either side of the constructionist/realist fence, it enabled him to adopt a distinctive vantage point on potentially threating uncertainties floating between emergence and harm, such as GMOs, nanotechnology and genetic cloning. Sørensen offers an account of the meaning and significance of risk for the production and interpretation of knowledge. What is interesting here is the very mobilization of the term 'risk' in the context of Beck's work. Drawing on personal correspondence, Sørensen makes clear that Beck was not primarily interested in risk in the contemporary sense of probability of exposure to harm. Rather, his social and political critique was oriented towards making sense of the seismic and transformative 'side-effects' of non-calculable uncertainties. He was always keen to develop and qualify his approach in the light of new knowledge. Following on from criticisms directed toward his apparent failure to distinguish between risk as a hypothetical possibility and material harms prevailing in contemporary society (see Mythen 2004; Nugent 2007) he distinguished between risk and catastrophe, explaining that: 'risk is not synonymous with catastrophe. Risk means the anticipation of the catastrophe. Risks concern the possibility of future occurrences and developments; they make present a state of the world that does not (yet) exist. Whereas every catastrophe is spatially, temporally and socially determined, the anticipation of catastrophe lacks any spatio-temporal or social concreteness' (Beck 
2009: 9). As with Luhmann (1993), firm semantic distinctions made between 'risk', 'catastrophe', or indeed 'danger', typically fail the test of ordinary language usage and collective understanding, but the sociological deployment of such categories nonetheless creates a tension which opens up key considerations of the social contingency and instrumental logics and structures of risk (Rosa 2003). In so doing, Beck (1992) lays bare the impossibility of externalizing risk and brings focused attention to new fundamental junctures of inequality and vulnerability that arise as byproducts of techno-economic development, as well as the increasing urgency of concerns about science and politics (Demeritt 2006). As Anders Blok reasons, the implications of these qualifications are significant, not least because critics have tended to overlook Beck's sustained efforts to concentrate on the impacts of 'manufactured uncertainties' on individuals and institutions (Beck 1999: 34; 2015; 2016). This was the transformative dimension of Beck's thesis in a nutshell. For him, the threats looming on the horizon were harbingers of a seismic transformation from a first, industrial modernity toward a second modernity, or risk society. The latter phase was characterized not only by constant flux, uncertainty and insecurity, but by inescapable self-reflexivity and institutional confrontation. For Beck, the 'side-effects' of the risk society are systemically generated and global. They cannot be avoided by recourse to the safety measures of the first modernity and their impacts are universal. In his words, 'there are no bystanders anymore' (Beck 1996: 32).

Building up rich case study pictures of the most effective strategies that might be mobilized to deal with potentially harmful situations in which limited or partial information is available remains one of the major challenges for researchers in risk studies (see Wardman and Mythen 2017). Both Sørensen and Mythen point toward the 
need for greater attention to institutional decision-making enacted in conditions of 'notknowing' (nichtwissen). Such practically useful knowledge can only be developed through exchanges between practitioners and academics. Like Sørensen, Mythen is similarly preoccupied with forms of institutional intervention which occur in conditions of non-knowledge and his analysis elucidates the possibilities of extending the reach of concepts of organized irresponsibility and nichtwissen. Mythen also draws attention to Beck's later attempts to understand the dynamics of representation and mediation in the social construction of risk. What is critical here - particularly in relation to terrorism is the cultural prevalence of dramatic staging (reälitatsinszenierung): 'with still relatively low numbers of victims and deeds, the felt violence and felt war are maximized and explode in the centres of the felt peace, both literally and in the mass media' (Beck 2009: 155). This observation highlights the salience Beck attached in later work to perceptions of risk in a Western context in which pervasive fears about 'worst imaginable accidents' are rife. For him, the anticipation of catastrophe was crucial in explaining modes of risk assessment, human responses and forms of regulation.

Situating Beck's work within the tradition of classical sociology, Daniel Levy's piece emphasizes the positive possibilities of risk in relation to the building of transnational collective bonds. For Levy, as for Beck, global risks are not auguries of Armageddon. Rather they provide the basis for transformations in values, politics, citizenship, culture and identity. While sensitive to the appropriation of risk by powerful actors and institutions - and maintaining alert to the atavistic emergence of neo-national tendencies - Levy shows how the formation of extra-national risk communities offers possibilities in terms of human bonds of solidarity and shared morals and ethics. In Beckian terms, 
the 'banal cosmopolitanization' of everyday life engenders routine engagements that advance both mutual understanding and the cultivation of common goods. For Levy, drawing on the principles and methods of 'methodological cosmopolitanism' is a precursor for better understanding the dynamics of the modern world and managing the risks and uncertainties on the horizon. Developing the concept of 'cosmopolitan catastrophism', Levy urges a continuation of Beck's efforts to map the diverse trajectories of risk societies in different regions of the globe.

Applying methodological cosmopolitanism to specific locales, Joy Zhang and Anders Blok offer distinct responses to Levy's challenge. Adopting a critical approach to the study of climate change, Blok deploys methodological cosmopolitanism to examine the emergent nature of 'urban-cosmopolitan risk communities'. Drawing on case studies in Europe and Asia, Blok underscores the importance of testing concepts and theories through application to specific sites and processes. It is significant that Blok, Levy and Zhang were part of an international team of researchers working with Beck to develop fresh theoretical and methodological approaches through grounded empirical studies. Central to this project has been a desire to understand the conditions under which new forms of relationships and socio-structural formations emerge and what these might mean for cultural and political transformation. Following this remit, Joy Zhang demonstrates in her article both the utility of methodological cosmopolitanism and an appreciation of the catalyzing value of Beck's challenge to the social sciences. Focusing on perceptions of traditional and novel food risks in the Chinese context, Zhang's study indicates that new cosmopolitan communities are clustering around specific issues. Extending knowledge on the situated and grounded nature of cosmopolitanization, Zhang shows how networked communities are capable of reimagining and redrawing 
the lines of risk definition. Her micro level analysis of citizen's involved in China's Good Food Movement offers a window into the lived experiences of individualization and risk. Adam Burgess's broader historical analysis compliments Zhang's evaluation of the impacts of individualization and details transitions and transformations in family structure and affective relationships in the United States and China. Noting the somewhat muted reception toward the 'other half' of the risk society thesis, Burgess highlights the ways in which modern 'elective affinities' in the United States are contingent upon personal choice, but remain impacted by class structure. In the case of China, it is posited that the complex forms of individualism that arise out of the marketstate relationship provide a peculiar version of the pattern of disembedding without reembedding which Beck was keen to emphasize.

Beck's throwing down of the methodological gauntlet is an issue pursued by Dean Curran in his summation of the 'creative challenge' he presented to class analysis. Aligning with Sørensen, Levy and Zhang, Curran is appreciative of Beck's mission to capture a world in motion and his willingness to revel in rather than shy away from ambiguity and ambivalence. Beck was insistent to the end that the social sciences should focus on the expansive 'both/and', rather than the mutually exclusive 'either/or' that cannot capture complexity. Tracing the history of Beck's ideas around the relationship between inequality and risk, Curran demonstrates the provocative nature of his intervention in this area and the productive capacity of the concept of risk-class for future analysis. The importance of transformation in Beck's work is again alighted upon here. For Beck, sociology in particular - and the social sciences in general - has suffered longstanding myopia in its acceptance of fixed categories and formations, such as the nation, the family and social class. It was his aim and ambition to facilitate modes 
and methods of inquiry that elucidated rather than denied the metamorphosis of institutions and social structures.

We hope that the articles in this special edition together showcase the scope and novelty of Beck's work. He was, indubitably, a pioneer who identified epoch making processes, including globalization, individualization, cosmopolitanism and reflexive modernization. Through collections such as this - and the projects of which they are a part of - the concepts and methods that Beck bequeathed the social sciences are set to live on and thrive. In as much as his preferred mode of projective social theory was designed to track the contours of the emergent and upcoming, his sustained engagement with colleagues around the globe led him to champion the importance of testing 'middle range theories' through grounded field studies (see Beck 2015; Blok 2015). What sets Beck's work apart is its ability to offer both methodological approaches and core concepts which are capable of capturing both macro structural transformations and micro level processes. The pieces of work assembled here bare testament to the applicability of Beck's theory to real world problems and issues, from food movements to family structure, terrorism to climate change. Beck was also one of very few sociological heavyweights happy to respond directly to intellectual challenge, which he saw as a progressive for knowledge production. Adaptability was one of his distinguishing characteristics. He held no truck with those merely seeking academic status and was always amenable to modifying his perspective or approach. Far from the vanity of ivory towered dogma that has blighted many a self-proclaimed luminary, Beck was generous with his praise and always willing to alter his viewpoint if persuaded by evidence to the contrary. His quest for knowledge and his thirst for 
unlocking the underlying dynamics of the modern age was indefatigable. Those whom he inspired will ensure that his legacy is secured and appreciated.

\section{References}

Beck, U. 2016. The Metamorphosis of the World. Cambridge: Polity.

Beck, U. 2015. "Emancipatory catastrophism: What does it mean to climate change and risk society?" Current Sociology 63 (1): 75-88.

Beck, U. 2009. World at Risk. Cambridge: Polity Press.

Beck, U. 1999. World Risk Society. Cambridge: Polity Press.

Beck, U. 1996. "Risk Society and the Provident State". In B. Szerszinski, S. Lash and B. Wynne. Eds. Risk, Environment and Modernity: Towards a New Ecology. London: Sage.

Beck, U. 1992. Risk Society: Towards a New Modernity. London: Sage.

Blok, A. 2015. "Towards cosmopolitan middle-range theorizing: A metamorphosis in the practice of social theory?" Current Sociology 63(1): 110-114.

Demeritt, D. 2006. "Science studies, climate change and the prospects for constructivist critique". Economy and society, 35 (3): 453-479.

Giddens, A. 2015. "Ulrich Beck: Obituary", viewable at: http://www.lse.ac.uk/sociology/pdf/Ulrich-Beck-obituary-by-Anthony-Giddens.pdf. Accessed July 3rd 2017.

Guivant, J. S. 2016. “Ulrich Beck's Legacy”, Ambiente and Sociedade, 19 (1): 18094422.

Kaldor, M. and Selchow, S. 2015. "Ulrich Beck Obituary" https://www.theguardian.com/education/2015/jan/06/ulrich-beck. Accessed 3rd July 2017. 
Luhmann, N. 1993. Risk: A Sociological Theory, Berlin.

Mythen, G. 2014. Understanding the Risk Society: Crime, Security and Justice.

London: Palgrave Macmillan.

Mythen, G. 2004. Ulrich Beck: A Critical Introduction to the Risk Society. London:

Pluto.

Rosa, E. A. 2003. "The logical structure of the social amplification of risk framework

(SARF): Metatheoretical foundations and policy implications”. In N. K. Pidgeon, R.E. and P. Slovic. Eds. The social amplification of risk. Cambridge: Cambridge University Press.

Wardman, J.K. and Mythen, G. 2017. "Risk Communication: Against the Gods or Against all Odds? Problems and Prospects of Accounting for Black Swans”. Journal of Risk Research. 19 (9): 1270-1281.

Nugent, S. (2000) “Good Risk, Bad Risk: Reflexive Modernisation and Amazonia”. In P. Caplan. Ed. Risk Revisited. London: Pluto. 